DOI: 10.17805/trudy.2017.4.2

\title{
ИННОВАЦИОННАЯ ДЕЯТЕЛЬНОСТЬ В УСЛОВИЯХ МАГИСТРАТУРЫ В ОБРАЗОВАТЕЛЬНОЙ СРЕДЕ ВУЗА
}

\author{
А. А. Фортунатов \\ Московский гуманитарный университет
}

\begin{abstract}
Аннотация: В данной статье раскрываются понятия инновация и инновационная деятельность. Рассматривается такой аспект учебно-познавательной деятельности обучающихся, как работа с электронным образовательным курсом, созданным на платформе Moоdle. Презентована программа дисциплины «Инновационная деятельность в современном образовании», направленная на формирование у обучающихся общепрофессиональных компетенций, методологическую подготовку магистрантов к внедрению инновационной деятельности в образовательную среду вуза.
\end{abstract}

Ключевые слова: инновация; инновационная деятельность; магистратура; образовательная среда; вузы

\section{INNOVATIVE ACTIVITY IN THE CONDITIONS OF POST-GRADUATE SCHOOL IN THE EDUCATIONAL ENVIRONMENT OF A UNIVERSITY \\ A. A. Fortunatov \\ Moscow University for the Humanities}

\begin{abstract}
The article develops the concepts of innovation and innovative activity. It considers such an aspect of students' educational and cognitive activity as work with the electronic educational course created on the Moodle platform. It presents the programme of the discipline "Innovative activity in modern education", which is aimed at the formation of students' all-professional competences, methodological training of graduate students for the introduction of innovative activity in the educational environment of the university.
\end{abstract}

Keywords: innovation; innovative activity; graduate school; educational environment; universities

На кафедре педагогики и психологии высшей школы АНО ВО «Московский гуманитарный университет» в процессе преподавания дисциплин в магистратуре используются различные инновационные методы и средства. В качестве примера, в данной статье, рассмотрим особенности преподавания дисциплины «Инновационная деятельность в современном образовании».

В начале остановимся на понятии «инновационная деятельность». Для того, чтобы более детально раскрыть данное понятие остановимся на содержании понятия «инновация». В «Современном словаре иностранных слов» понятие «инновация» (лат. in - «в», novus - «новый») понимается как нововведение (Современный словарь иностранных ..., 2011: 348).

Интерес для нас представляет исследование классификации «инновации», проведенное Т. В. Голяковой, которая отмечает, что часть 
авторов рассматриют ее как процесс или действие (В. Г. Медынский, Ф. Валента, Ф. Никсон и др.), другие видят ее как объект или результат научно-исследовательсокй деятельности, реализоавнный в виде конечного продукта или технологии (3. А. Уткин, Ш. Гохберг и др.) (Голдякова, 2006: 20-21).

Наиболее близка к нам точка зрения В. А. Лукова, который отмечает, что «Инновация - не просто придуманное новое, а новое внедренное или по крайней мере приготовленное к внедрению в жизнь. Хотя способность к креативу и лежит в основе инновации, но востребована она избирательно и в рамках, приемлемых для системы, которой предстоить освоить инновацию. Из этого следует, среди прочего, и то, что способность к креативу вовсе не константа молодежи, она нарастает и ослабевает по ситуации востребования. Но более важно, что даже выделенная из новационных свойств молодежи ее инновационность выступает как потенция, которая в той или иной мере регулируется обществом» (Луков В., Луков С., Погорский, 2014: 12). С этим мнением трудно не согласиться.

Инновация, по мнению В. И. Винокурова, представляет собой результат инновационной деятельности, получивший воплощение в виде нового или усовершенствованного продукта, внедренного на рынке, нового или усовершенствованного технологического процесса, используемого в практической деятельности, либо нового или усовершенствованного организационно-экономической формы, обеспечивающей необходимую экономическую и общественную выгоду (Винокуров, 2005: 8).

Таким образом, понятие «инновация» часто трактуется как особый вид деятельности, а именно - инновационной.

Существующие на данный момент определения инновационной деятельности, в основном, различающиеся перечнем видов работ, включаемых в нее. Мы рассмотрим опыт применения инноваций в образовательной среде вуза.

Согласно «Стратегии инновационного развития Российской Федерации на период до 2020 г.», одной из основных задач инновационного развития в области образования является создание условий для формирования у обучающихся следующих компетенций инновационной деятельности:

- способность и готовность к непрерывному образованию, постоянному совершенствованию, переобучению и самообучению, профессиональной мобильности, стремление к новому;

- способность к критическому мышлению;

- способность и готовность к разумному риску, креативность и предприимчивость, умение работать самостоятельно, готовность к работе в команде и в высококонкурентной среде; 
- владение иностранными языками, предполагающее способность к свободному бытовому, деловому и профессиональному общению (Стратегия инновационного ..., 2011: Электр. ресурс).

На сегодняшний день можно говорить о разнообразных инновациях, внедряемых в высших учебных заведениях. По мнению Н. В. Тельтевской, к ним можно отнести:

- организационно-управленческие, включающие в себя принятие стандартов высшего профессионального образования, реформирование системы высшего профессионального образования, подготовку к переходу на новые международные стандарты качества;

- экономические инновации, характеризующиеся повышением заработной платы и наличием стимулирующих надбавок к ней, повышением стипендии обучающимся. Сюда же входит процесс интеграции и автономизации вузов;

- социальные инновации, заключающиеся в создании попечительских советов, спонсорства, взаимодействием с социальными партнерами;

- организационно-педагогические, предусматривающие реализацию учебных планов и программ в соответствии с требованиями ФГОС нового поколения, разработку и внедрение инноваций в содержании, методах и формах обучения. Особенностью современных учебных программ, создаваемых на компетентностной основе, является направленность на использование интерактивных форм и методов обучения (Тельтевская, 2016: 58).

Как показывает практика, в процессе обучения в магистратуре необходимо применение инновационных педагогических технологий, к которым можно отнести: игровые, компьютерные, модульные, технологии контекстного обучен, интенсивные технологии, технологии рейтингового контроля и оценки знаний обучающихся и т. д.

Особую роль в обучении магистра играет обучение самостоятельной работе. Самостоятельная работа магистра представляет собой неотъемлемую и важную составляющую учебного процесса в сфере, которая связывает все методы и формы обучения между собой. Данный вид работы следует рассматривать, как вид учебно-познавательной деятельности, которая стимулирует потребность к самообразованию, самообучению и непрерывному профессиональному совершенствованию. Поэтому в процессе обучения должна осуществляться целенаправленная подготовка магистров к самообразованию, что можно сделать в процессе постоянного выполнения ими различных видов самостоятельной работы. С этой целью, как пишет Н. В. Тельтевская, необходимо применять инновационные технологии в процессе организации самостоятельной работы обучающихся. К ним, по мнению автора, можно отнести: телекоммуникационный учебный проект, создание WEB-KBECTA, диалектические заметки, самостоятельные твор- 
ческие задания, метод «Создание шпаргалки», метод консультирования, составление текстовых заданий и др. (Тельтевская, 2015).

В качестве примера изучения, применения и использования инновационной деятельности в вузовской среде можно рассмотреть освоение магистрантами дисциплины «Инновационная деятельность в современном образовании». Данная дисциплина «входит в вариативную часть учебного плана по направлению подготовки 44.04.02 - «Психологопедагогическое образование» ОП магистратурым и реализуется в МосГУ с 2014 года.

Процесс изучения данной дисциплины направлен на формирование профессиональной компетенции (ПК-34) - способности выделять актуальные проблемы развития современной системы образования, обучения и развития обучающихся.

В соответствии с требованиями стандарта программа дисциплины «Инновационная деятельность в современном образовании» направлена на формирование прописанной компетенции и имеет целью формирование у обучающихся-магистрантов способности к инновационной деятельности в области педагогики и психологии высшей школы.

Цель изучения дисциплины конкретизируется в задачах:

- сформировать систему научных знаний об инновационной деятельности образовательных учреждений, связанной с разработкой и внедрением педагогических и управленческих новшеств, обеспечивающих модернизацию российского образования, повышение его качества;

- раскрыть понятийный аппарат инноватики в области педагогики, методы организации и экспертной оценки инновационной деятельности образовательных учреждений;

- развивать научное, аналитическое, рефлексивное мышление будущих магистров, развитие исследовательских, конструктивных, прогностических компетенций;

- формировать понимание значимости инновационной деятельности как основного механизма модернизации образования в современном социуме; личностную готовность обучающегося к включению в инновационный процесс, ориентированный на высокое качество образовательных услуг.

В результате изучения дисциплины «Инновационная деятельность в современном образовании» обучающийся должен:

1. Знать:

- требования к экспертизе образовательных программ, современной системы образования, обучения и развития обучающихся, педагогических технологий и проектов инновационной деятельности в образовательных учреждениях; 
- психолого-педагогические условия, способствующие внедрению инновационного процесса в образовательную систему;

- специфику работы с коллективом образовательного учреждения по формированию готовности к инновационным изменениям;

- особенности взаимодействия по разработке планов инновационного развития между руководителем образовательного учреждения и пелагическим коллективом с одной стороны и родителями обучающихся с другой стороны.

2. Уметь:

- оценивать и разрабатывать инновационные проекты, направленные на повышение эффективности образовательного процесса и развитие обучающихся;

- взаимодействовать с коллективом в процессе проектноисследовательской инновационной деятельности, направленной на повышение качества образовательных услуг, развития современной системы образования, обучения и развития обучающихся;

- выделять актуальные проблемы развития современной системы образования, обучения и развития обучающихся.

3. Владеть:

- навыками создания психолого-педагогических проектов инновационной деятельности в образовательных учреждениях, направленных на повышение качества образования, способствующих повышению качества взаимодействия участников образовательного процесса;

- способностью выделять актуальные проблемы развития современной системы образования, обучения и развития обучающихся.

- навыками участия в профессиональных дискуссиях по инновациям в сфере образования, аргументировано отстаивать свою точку зрения (Фортунатов, 2016: 6).

В программу дисциплины включено рассмотрение на лекциях, практических занятиях, а также самостоятельно следующих вопросов:

1. Развитие инновационных процессов как способ обеспечения модернизации образования, повышения его качества, эффективности и доступности;

2. Этапы развития инновационной педагогической деятельности в России;

3. Педагогическая инноватика как самостоятельная научная дисциплина;

4. Сущность понятия «инновация» в отечественной педагогической науке;

5. Виды инноваций в образовании;

6. Инновационная деятельность в образовательном учреждении: 
сущность и содержание;

7. Основные этапы инновационного процесса;

8. Инновационный проект, программа и план реализации инновационного проекта;

9. Структура инновационного проекта в сфере образования;

10. Система управления инновацией в образовательном учреждении, программа и план реализации инновационного проекта;

11. Экспертиза процесса и результатов инновационной деятельности;

12. Критерии и показатели как основа экспертной оценки педагогической инновации;

13. Технология метода экспертной оценки инноваций в образовании. Педагогический эксперимент: сущность, основные этапы (там же).

Также хотелось отдельно остановиться на опыте внедрения инновации в образовательный процесс АНО ВО «Московский гуманитарный университет» (МосГУ). В процессе изучения тем по дисциплине «Инновационная деятельность в современном образовании» особый интерес представляет рассмотрения электронных образовательных курсов, разработанных в МосГУ на базе программы Moodle. Так, например, разработанный профессором кафедры педагогика и психология высшей школы B. А. Ситаровым курс «Педагогика и психология ненасилия» представляет собой комплекс лекций, практических занятий, а также проверочных материалов к ним (вопросов для самостоятельной подготовки, тестов и тем презентаций). Студенты, изучающие данный курс, могут самостоятельно подготовиться к предстоящим занятиям или в случае отсутствия на лекциях зайти на данный курс и пройти пропущенную тему.

Данная программа позволяет преподавателю, разработавшим данным курс, в онлайн режиме просматривать ответы студентов и выставлять им оценки за пройденные тесты. Кроме того, можно проследить, когда студент заходил на страничку курса и что он делал на ней. Преподаватель может ограничить количество возможных попыток для сдачи тестов или ограничить время за которое студент может пройти ту или иную тему данного курса. Платформа Moodle позволяет отрегулировать функцию, чтобы студенты видели, либо не видели свои оценки по изучаемому им предмету.

Подводя итоги вышесказанному следует отметить, что реализация в полном объеме представленной программы дисциплины «Инновационная деятельность в современном образовании» позволяет подготовить обучающихся к успешному осуществлению инновационной деятельности в образовательной среде вуза. Также необходимо сказать, что внедрение инновационной деятельности в подготовку магистров может осуществляться по различным направлениям и является неотъемлемой частью формирования гармонично-развитой личности. 


\section{СПИСОК ЛИТЕРАТУРЫ}

Винокуров, В. И. (2005) Основные термины и определения в сфере инноваций // Инновация. № 4 (81). С. 6-22.

Голдякова, Т.В. (2006) Понятие и классификация инноваций // Российский внешнеэкономический вестник. №2. С. 20-27.

Луков, В. А., Луков, С. В., Погорский Э. К. (2014) Инновационный потенциал новых поколений и молодежная политика на современном этапе развития общестсва // Politbook. № 2. С. 6-18.

Тельтевская, Н. В. (2016) Внедрение инноваций в учебный процесс как условие готовности студентов к непрерывному образованию // Грани познания. № 3 (46). С. 57-62.

Тельтевская, Н. В. (2015) Инновационные формы и методы обучения в вузе: метод. пособие. Саратов : ИЦ «Наука». 172 с.

Современный словарь иностранных слов (2011) / под ред. Т. Федотова. М. : ЛадКом. 704 с.

Стратегия инновационного развития Российской Федерации на период до 2020 года (2011) [Электронный ресурс] // Минкомсвязь РФ. URL: http://minsvyaz.ru/common/upload/2227-pril.pdf (дата обращения: 14.05.2017).

Фортунатов А. А. (2016) Рабочая программа дисциплины «Инновационная деятельность в современном образовании» Б1.В.ОД.1 Направление подготовки - 44.04.02 «Психолого-педагогическое образование Квалификация выпускника - магистр Форма обучения - очная, заочная. М.: Изд-во МосГУ. 39 с.

Дата поступления: 20.06.2017 2.

Фортунатов Артем Александрович - кандидат педагогических наук, доцент кафедры педагогики и психологии высшей школы Московского гуманитарного университета. Адрес: 111395, Россия, г. Москва, ул. Юности, д. 5 Тел.: +7 (499) 374-74-59. Эл. адрес: art_fortunatov@mail.ru

Fortunatov Artyom Aleksandrovich, Candidate of Pedagogy, Associate Professor, Department of Pedagogy and Psychology of Higher School, Moscow University for the Humanities. Postal address: 5, Yunosti St., Moscow, Russian Federation 111395. Tel.:+7 (499) 374-74-59.E-mail: art_fortunatov@mail.ru

\section{Для цитирования:}

Фортунатов А. А. Инновационная деятельность в условиях магистратуры в образовательной среде вуза [Электронный ресурс] // Научные труды Московского гуманитарного университета. 2017, № 4. URL: http://journals.mosgu.ru/trudy/article/view/525 (дата обращения: дд.мм.гг.). DOI: 10.17805/trudy.2017.4.2 